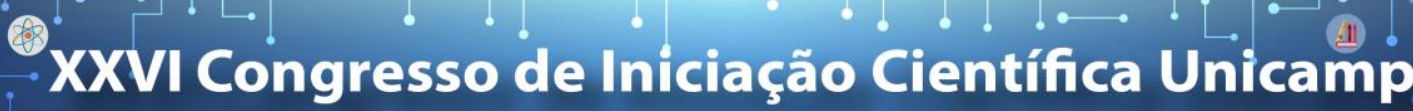

8)

\author{
17 a 19 de outubro Campinas | Brasil
}

\section{ASSOCIAÇÃO ENTRE DESEMPENHO ESCOLAR, ESTADO DE SAÚDE E VARIÁVEIS PSICOSSOCIAIS EM ESCOLARES DO ENSINO MÉDIO DO MUNICÍPIO DE PIRACICABA}

\section{Abia Reami Alves, Agnes Pezzan, Ana Clara Simon, Juan Felipe Pires do Prado, Luana Togni de Goes, Midiâ Sabrina Freire de Lima, Fábio Luiz Mialhe.}

\section{Resumo}

O objetivo deste projeto de pesquisa foi de avaliar, por meio de um estudo transversal observacional, as associações entre características de saúde e psicossociais de adolescentes e o rendimento escolar. Participaram da pesquisa, 250 adolescentes na faixa etária de 14 a 18 anos, de ambos os sexos, provenientes de 5 escolas públicas do ensino médio do município de Piracicaba, SP. Foram aplicados, em semanas distintas, os seguintes questionários: características sociodemográficas (sexo, idade, moradia etc.), autopercepção do rendimento escolar e autopercepção da saúde bucal; senso de coerência; resiliência; bullying e letramento em saúde bucal. Verificou-se que as indivíduos do sexo masculino, que autoreferiram um estado de saúde geral ruim, que foram ao dentista pela última vez devido a problemas odontológicos e que apresentavam baixo letramento em saúde bucal apresentaram maior chance de apresentarem um baixo rendimento escolar $(p<0,001)$.

Palavras-chave: Baixo rendimento escolar, saúde bucal, alfabetização em saúde.

\section{Introdução}

O objetivo deste estudo foi avaliar a associação de algumas variáveis, incluindo desfechos em saúde no rendimento escolar. Após a coleta dos dados em 5 escolas com 250 escolares, foi realizada inicialmente uma análise univariada via teste Qui-Quadrado. Posteriormente, foi ajustado um modelo multivariado de regressão logística, aplicado o método Backward e adotado um nível de $5 \%$ de significância. Para avaliar a qualidade do ajuste da regressão logística utilizou-se o teste de Hosmer-Lemeshow (Hosmer e Lemeshow, 2000) e o pseudo $R^{2}$ de Nagelkerke (Nagelkerke, 1991).O software utilizado nas análises foi o $R$ (versão 3.4.3).

\section{Resultados e Discussão}

Verificou-se que a maioria dos indivíduos $(62,8 \%)$ era do sexo feminino; $61,5 \%$ moravam com os pais biológicos; a maior parte dos alunos $(67,82 \%)$ morava com até 4 pessoas; $83,5 \%$ dos indivíduos consideraram o estado geral de saúde excelente/muito boa/boa; $86,2 \%$ dos indivíduos teve como motivo da última visita ao dentista a consulta rotina/limpeza; o escore médio do instrumento de letramento em saúde bucal foi de 47,4 (bom) e 57,1\% dos alunos apresentaram excelente/bom rendimento escolar.

A análise de regressão logística multivariada (Tabela 1) indicou que:

- Houve influência significativa do sexo (valor- $p=0,000$ ) sobre o rendimento escolar, sendo que a chance dos alunos do sexo masculino apresentarem um excelente/bom rendimento foi $63 \%$ menor que a chance dos alunos do sexo feminino.

- Houve influência significativa do estado de saúde (valor$p=0,017$ ) sobre o rendimento escolar, sendo que a chance dos alunos com estado de saúde regular/ruim apresentarem um excelente/bom rendimento foi $58 \%$ menor que a chance dos indivíduos com estado de saúde excelente/muito boa/boa.

- Houve influência significativa (valor- $p=0,008$ ) do motivo da última visita ao dentista sobre o rendimento escolar, sendo que a chance dos alunos que foram ao dentista por motivo de Restaurações/Extrações/Tratamento dor apresentarem rendimento excelente/bom foi $65 \%$ menor que a chance dos alunos que foram ao dentista por motivo de consulta rotina/limpeza.

- Houve influência significativa do letramento da saúde bucal (valor- $p=0,004$ ) sobre o rendimento escolar, sendo que a chance dos alunos com letramento bucal acima de 49 apresentarem um excelente/bom rendimento foi 2,17 vezes maior que a chance dos alunos com letramento bucal menor ou igual a 49.

Tabela 1. Modelo logístico inicial e final para o rendimento escolar.

\begin{tabular}{|c|c|c|c|c|c|c|}
\hline \multirow{2}{*}{ Variáveis } & \multicolumn{3}{|c|}{ Modelo Inicial } & \multicolumn{3}{|c|}{ Modelo Final } \\
\hline & O.R. & I.c. $95 \%$ & $\begin{array}{c}\text { Valor- } \\
\mathrm{p}\end{array}$ & O.R. & I.C. $95 \%$ & $\begin{array}{c}\text { Valor- } \\
\mathrm{p}\end{array}$ \\
\hline & 1,00 & - & - & 1,00 & - & - \\
\hline Sexo=Masculino & 0,37 & $\begin{array}{l}{[0,21 ;} \\
0,64]\end{array}$ & 0,000 & 0,37 & $\begin{array}{l}0,21 ; \\
0,65]\end{array}$ & 0,000 \\
\hline Com quem você mora=Pais biológicos & 1,00 & - & - & - & - & - \\
\hline Com quem você mora=Outros & 0,63 & $\begin{array}{l}0,36 ; \\
1,09] \\
\end{array}$ & 0,098 & - & - & - \\
\hline Quantas pessoas moram com você=Até 4 pessoas & 1,00 & - & - & - & - & - \\
\hline $\begin{array}{l}\text { Quantas pessoas moram com você }=5 \text { pessoas ou } \\
\text { mais }\end{array}$ & 1,65 & $\begin{array}{l}{[0,92 ;} \\
2,95]\end{array}$ & 0,093 & - & - & - \\
\hline Estado de saúde=Excelente/Muito boa/Boa & 1,00 & - & - & 1,00 & - & - \\
\hline Estado de saúde=Regular/Ruim & 0,42 & {$[0,2 ;$} & 0,021 & 0,42 & $\begin{array}{l}{[0,2 ;} \\
0,86] \\
\end{array}$ & 0,017 \\
\hline $\begin{array}{l}\text { Motivo última visita dentista=Consulta } \\
\text { rotina/Limpeza }\end{array}$ & 1,00 & - & - & 1,00 & - & - \\
\hline $\begin{array}{l}\text { Motivo última visita } \\
\text { dentista=Restaurações/Extrações/Tratamento }\end{array}$ & 0,37 & $\begin{array}{l}{[0,17} \\
0,81]\end{array}$ & 0,013 & 0,35 & $\begin{array}{l}{[0,16 ;} \\
0,76]\end{array}$ & 0,008 \\
\hline $\begin{array}{l}\text { Contentamento com a aparência dos } \\
\text { dentes=Contente }\end{array}$ & 1,00 & - & - & - & - & - \\
\hline $\begin{array}{l}\text { Contentamento com a aparência dos dentes=Não } \\
\text { contente }\end{array}$ & 0,98 & $\begin{array}{l}{[0,5 ;} \\
1,89] \\
\end{array}$ & 0,942 & - & - & - \\
\hline Letramento da saúde bucal=Menor ou igual a 49 & 1,00 & - & - & 1,00 & - & - \\
\hline Letramento da saúde bucal=Maior que 49 & 2,23 & $\begin{array}{l}{[1,29 ;} \\
3,86]\end{array}$ & 0,004 & 2,17 & $\begin{array}{l}{[1,28 ;} \\
3,69]\end{array}$ & 0,004 \\
\hline Pseudo $R^{2}$ (Negelkerke) & \multicolumn{3}{|c|}{$19,75 \%$} & \multicolumn{3}{|c|}{$16,97 \%$} \\
\hline Teste de Hosmer-Lemeshow (valor-p) & \multicolumn{3}{|c|}{0,810} & \multicolumn{3}{|c|}{1,000} \\
\hline
\end{tabular}

\section{Conclusões}

O rendimento escolar esteve associado a variáveis sociodemográficas, de saúde e de letramento em saúde.

\section{Referências:}

Paula JS et al. School performance and oral health conditions: analysis of the impact mediated by socioeconomic factors. Int J Paediatr Dent. 2016 Jan;26(1):52-9.

Kanupuru KK, Fareed N, Sudhir KM. Relationship Between Oral Health Literacy and Oral Health Status Among College Students. Oral Health Prev Dent. 2015;13(4):323-30. 